\title{
Coulisses
}

Revue de théâtre

6 | Printemps 1992

Varia

\section{Je suis allée voir le cirque Plume...}

\section{Claire Garbagnati}

\section{OpenEdition}

Journals

Édition électronique

URL : http://journals.openedition.org/coulisses/1862

DOI : $10.4000 /$ coulisses. 1862

ISSN : 2546-9460

\section{Éditeur}

Presses universitaires de Franche-Comté

\section{Édition imprimée}

Date de publication : 1 juin 1992

ISSN : 1150-594X

\section{Référence électronique}

Claire Garbagnati, « Je suis allée voir le cirque Plume... », Coulisses [En ligne], 6 | Printemps 1992, mis en ligne le 15 mars 2019, consulté le 21 octobre 2019. URL : http://journals.openedition.org/coulisses/ 1862 ; DOI : 10.4000/coulisses.1862

Ce document a été généré automatiquement le 21 octobre 2019.

Coulisses 


\section{Je suis allée voir le cirque Plume...}

\section{Claire Garbagnati}

Le Cirque Plume est né officiellement en 1984 avec un groupe de 9 artistessaltimbanques, un chapiteau de 200 places, un spectacle influencé par les arts de la rue : jongleries, accordéon et saxophone, acrobaties. Aujourd'hui, le Cirque Plume, c'est une équipe de 35 personnes dont 14 artistes, un chapiteau de 800 places, des titres honorifiques avec le Grand Prix National du cirque obtenu en 90. Son nouveau spectacle No animo mas anima a été présenté dans différentes villes de France, à l'étranger et... à Besançon, ville natale de la Compagnie.

Le Cirque Plume 

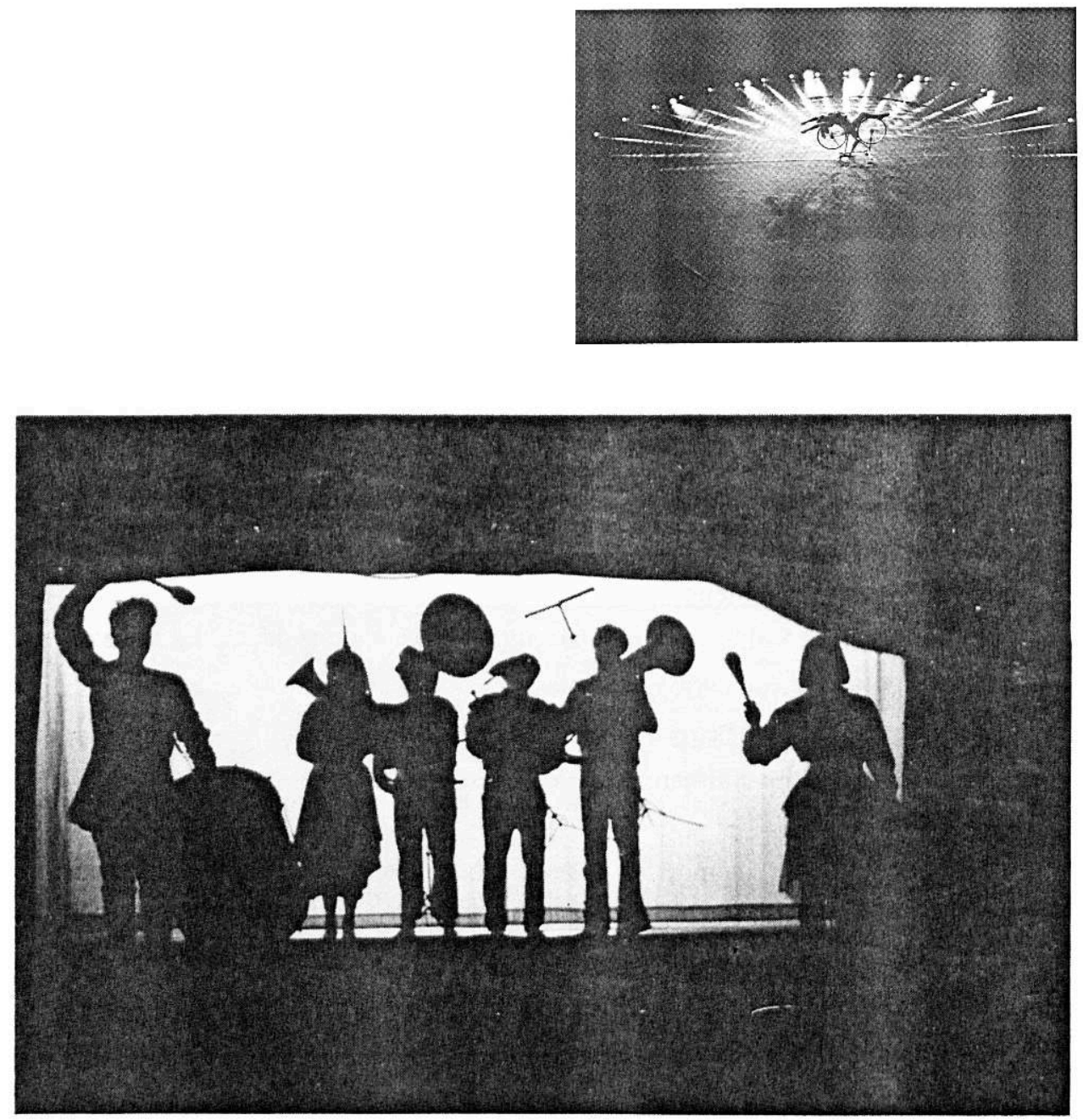

Photo Yves Perton

1 Non! La Plume ne s'était pas envolée et avait même dressé son chapiteau pour quelques jours, du 16 au 30 avril, place Leclerc... Avis à la concurrence alors même que retentissaient les flonflons de la fête foraine place Battant, encouragés par une météo correcte voire ensoleillée.

2 Bref, assez fatiguée et plutôt encline à plonger sous la couette, je m'étais hissée jusque là. Le temps d'une soirée, j'ai troqué mon duvet d'oie pour une autre sorte de plume.

3 Mais le cirque a pris le parti de nous faire rêver, et là, aucun risque de cauchemar... L'unique réveil retentissant interrompant une nuit magique consistait ici en l'arrivée inopinée d'un fauve, humain rugissant et vociférant à souhait, d'un sale bambin tout fier de s'écraser le front sur le tabouret ou encore d'une colonie de papillons, dont seul l'ignoble chasseur à l'épuisette était en mesure de faire taire les caquetages et piaillements.

4 Même si, la troupe se professionnalisant et la technique progressant, je regrette un peu les séquences de « cirque traditionnel », l'originalité, le burlesque et l'inattendu sont 
toujours au rendez-vous : on dompte une fanfare, l'écuyère danse sur sa bicyclette et le chien savant baille en public.

5 Si le spectacle est haut en couleurs, la plume n'est pas pour autant une plume de Paon. Le succès ne leur a pas fait perdre leur fraîcheur et on ne se prend pas au sérieux.

Les artistes du Cirque Plume

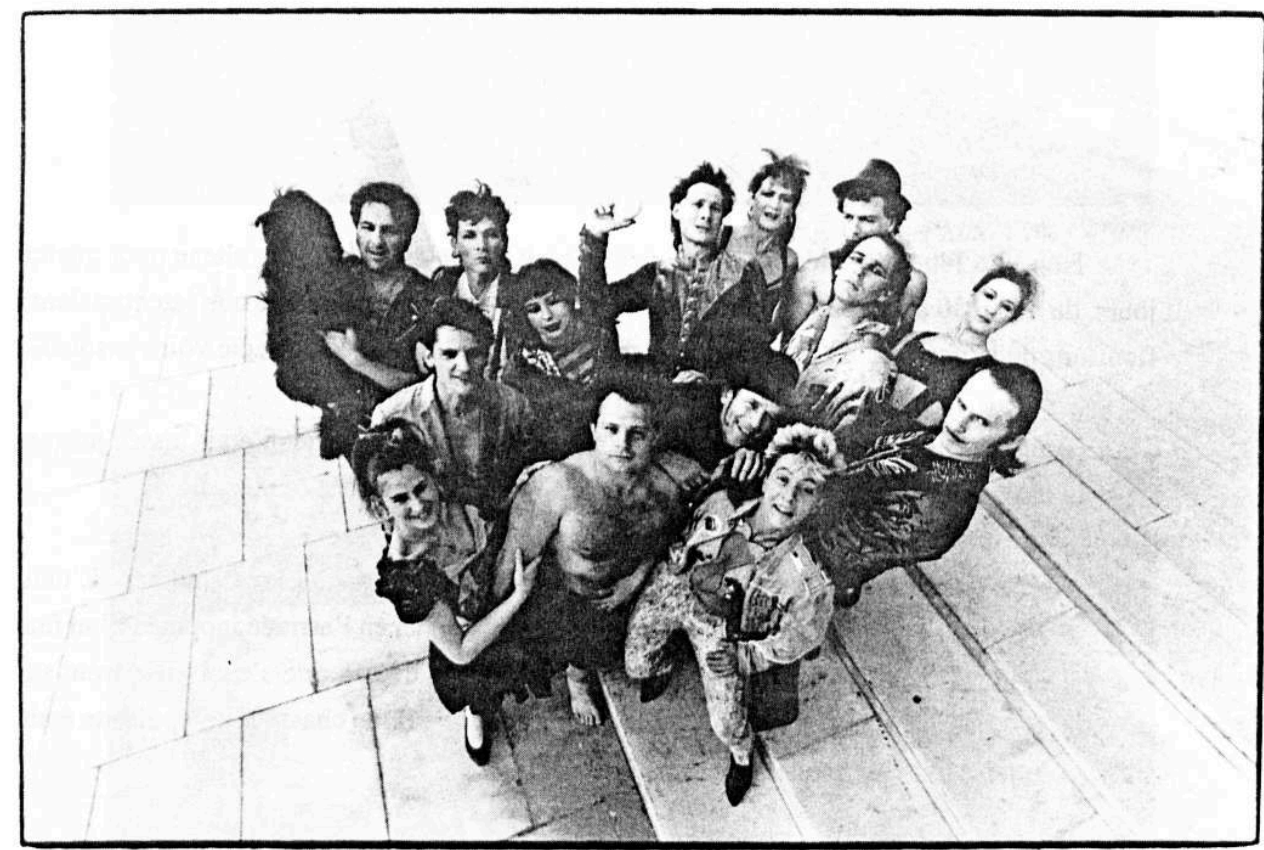

Photo Yves Perton 